$$
\begin{aligned}
& \text { Conf }-90071 / 7 \ldots 4 \\
& \text { OCRL-JC--105105 } \\
& \text { DE91 } 012081 \\
& \text { MAY } 311991
\end{aligned}
$$

\title{
Radio Frequency and Microwave Plasma for Optical Thin Film Deposition
}

\author{
J. Otto, V. Paquet, R. Th. Kersten, H.-W. Etzkorn \\ R. M. Brusasco, J. Britten, J. H. Campbell, and J. B. Thorsness
}

This paper was prepared for submittal to SPIE Conference

San Diego, CA

July 1990

October 18, 1990

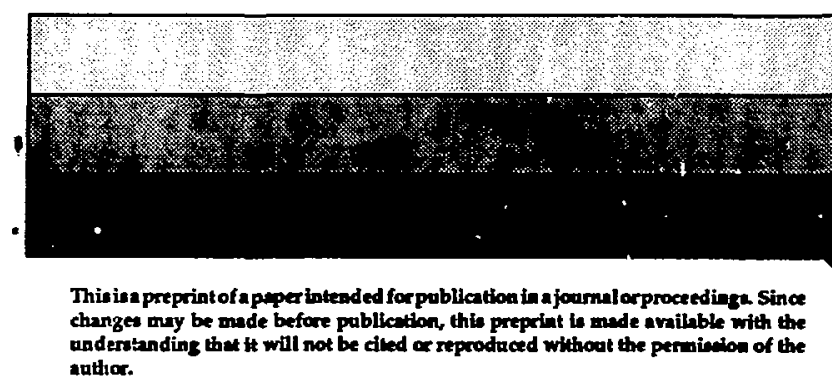

This is a preprintof a peperinteaded for poblication in a journal orproceedinga since underatanding that $t \mathrm{f}$ will not be ciled or reproduced withool the pernincion of the autior.

\section{- MASTEP}

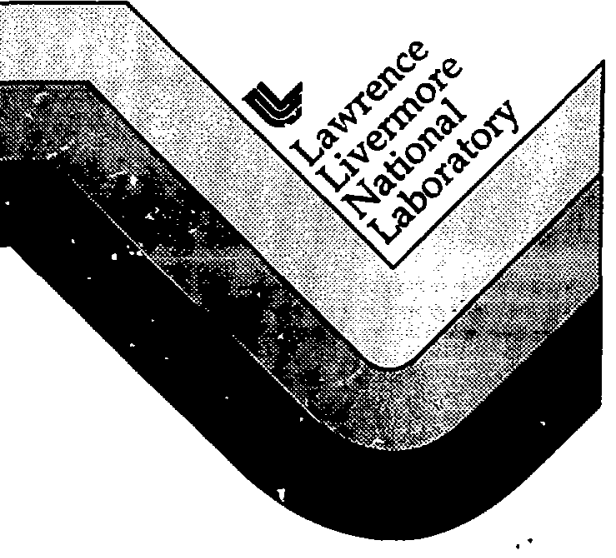


DISCLAHE⿰亻E

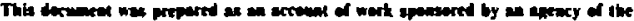

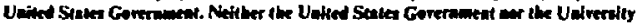

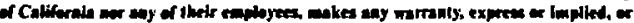

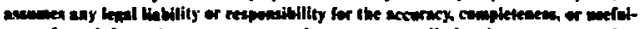

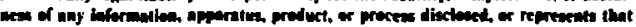

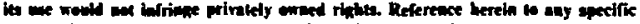

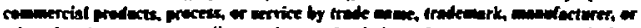

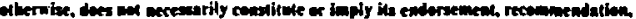

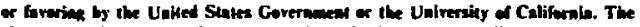

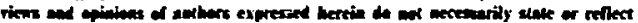

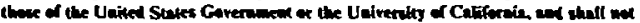

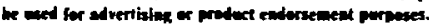

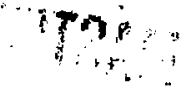


Radio frequency and microwave plasma for optical thin film deposition *

J. Otto, V. Paquet, R. Th. Kersten, H.-W. Etzkorn

SCHOTT Glaswerke, D-6500 Mainz, W.-Germany

R. M. Brusasco, J. Britten, J. H. Campbell, J. B. Thorsness

Lawrence Livermore National Laboratories, Livermore, CA, USA

\section{Introduction}

For the next generation of fusion lasers reflecting mirrors with laser damage thresholds of at least $40 \mathrm{~J} / \mathrm{cm}^{2}$ for $10 \mathrm{~ns}$ laser pulses at $1.064 \mu \mathrm{m}$ are needed. Up to now, no deposition techniquie has been developed to produce such mirrors. Best AaD-values realized today are around $30 \mathrm{~J} / \mathrm{cm}^{2}$ for e-beam evaporated mirrors. R\&D on conventlonal e-beam coating processes over the last 10 years. has come up with marginal improvements in laser damage thresholds only. However, new technologles, like PICVD (Plasma-Impulse CVO) developed for the fabrication of ultra-low loss fiber prelorms, seem to offer the potential to solve this problem. First results have been reported already [1-3]. It is well known that fused silica produced by CVD processes can have laser damage thresholds as high as $80 \mathrm{~J} / \mathrm{cm}^{2}$. However, the thickness of a single deposited film is in the $\mu$ m-range for most of the CVD-processes used for preform manufacturing: since interference optics need films in the $\lambda /$ an range (where $n$ is the refractive index of the dielectric material) the use of preform-fabrication processes for the purpose of interference mirror fabrication is limited to a few plasma based CVD technologies, namely PCVD (Plasma-CVD, Philips [4]; PICVD, SCHOTT [5]). Especially PICVD is a very powertul technology. to fabricate thin film multilayers for interference mirrors, because this technique is able to produce films down to monolayer thickness with nearly perfect stoichiometry and morphology. In first and preliminary experiments the usual deposition in a circular tube at high temperatures has been used for simplicity. However, to produce large area high quality laser mirrors this principle know-how has to be transfered from circular to planar geometry. Experiments showed, that there may be some lirritations with respect to the homogenelty of a planar deposition using microwave excitation for the plasma. Therefore experiments have been performed in parallel with both RF and microwave excitation for comparison. In the following we will restrict ourselves to the description and discussions of the planar processes; the principle and details of the PICVD-process are described elsewhere [5] while RF-plasma technology is a well known process.

\section{Multilayers}

A multilayer can be prepared by a CVO-process by perlodically mixing $\mathrm{SlO}_{2}$ precursor gas flow with dopant precursor gas flows. This leads to a jerlodical doping of the growing $\mathrm{SiO}_{2}$ layer. Thermal mismatch of pure and doped $\mathrm{SiO}_{2}$ limits the refractive index difference which can be produced by

*This work was performed under the auspices of the U.S. Department of Energy

by Lawrence Livermore National Laboratory under contract No. W-7405-Eng-48. 
the doping. Hign reilectance can nevertheless the achieved by fabrication of a large number of layer pairs. This also meets the consideration that multilayers for high power lasers should be constructed such as to avoid strong field enhancements at the boundary of high and low refractive index layers, 1. e. small index difference as well as very small index gradient should be used. Therefore a sinusoidal refractive index profile should be prefered [6].

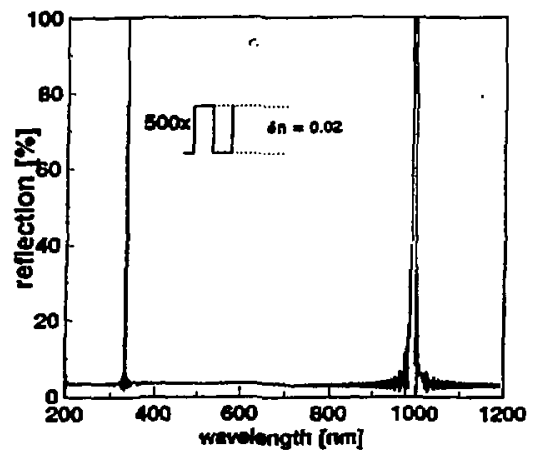

Fig. 1: Reflection curve of a 500 periods filter with rectangular refractive index change and $\delta \mathbf{n}=0.02$

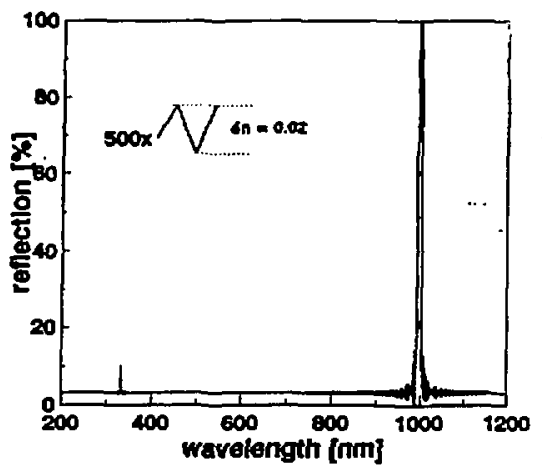

Fig. 2: Reflection curve of 500 periods filter with triangular refractive index change and $\delta n=$ 0.02

\subsection{Theorelical calculations}

Reflection spectra of low refractlve index difference filters (LRIDF) have been calculated for various shapes of refractlve index profiles and - for simplicity - for a peak wavelength of $1 \mathrm{fm}$. Rectangular and triangutar proflles (Flgs. 1, 2) do not show the first but the second harmonic only. A pure sinusoidal LRIDF, a so called Rugate-filter [6], however, has no harmonics, If the refractive index difference is small compared to the perlod number (Flg. 3); If not, the first harmonic appears at $\lambda_{0} / 2$ (Fig. 4). Harmonlos at $\lambda_{0} / 2$ result also from disturbed (change in period) sinus profiles (Figs. 5 a,b).

In all cases the reflection is very high. 

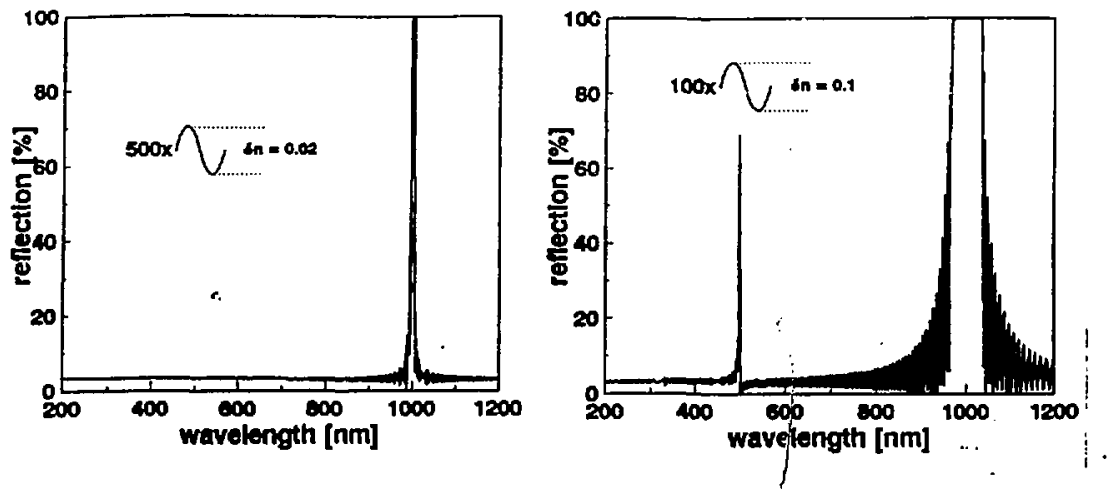

Fig. 3: Reflection curve of a 500 periods filter with sinusoidal refractive index change and $\delta n=0.02$

Fig. 4: Reflection curve of a 100 periods filter with sinusiidal refractive index change and $\delta n=$ 0.1
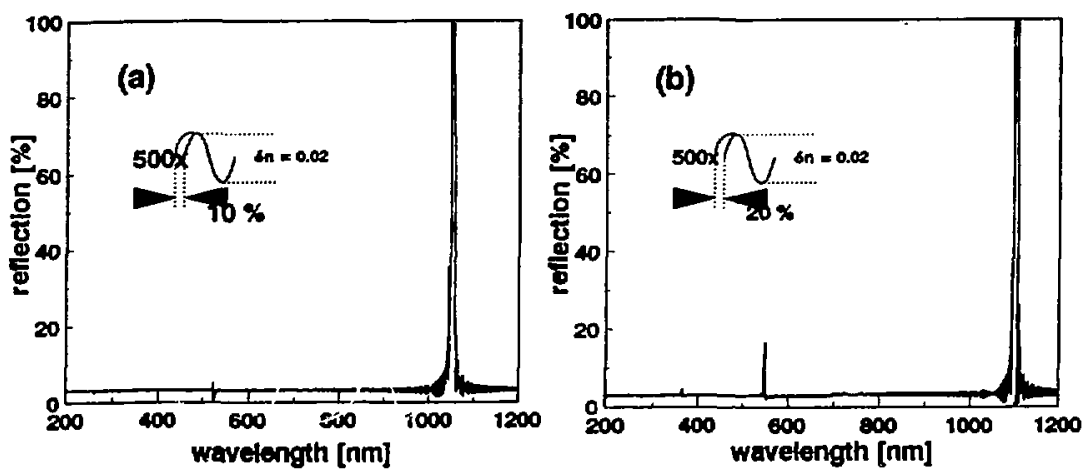

Fig. 5: Same as Fig. 3 but disturbations of $10 \%$ (a) or $20 \%$ (b) of the periog length 


\subsection{General practical aspects of mirror preparation}

Conventional mass flow controlers used for the experiments described here are not at ail able to form doping-gas mass flows having the same wayeform as the corresponding set points. A square waveform setpoint forms a mass flow with a smooth rise and a steep descent. The peaks of a mass flow formed by a triangle waveform are rounded and the mass flow formed by a sinusoidal waveform is (slightly) deformed too.

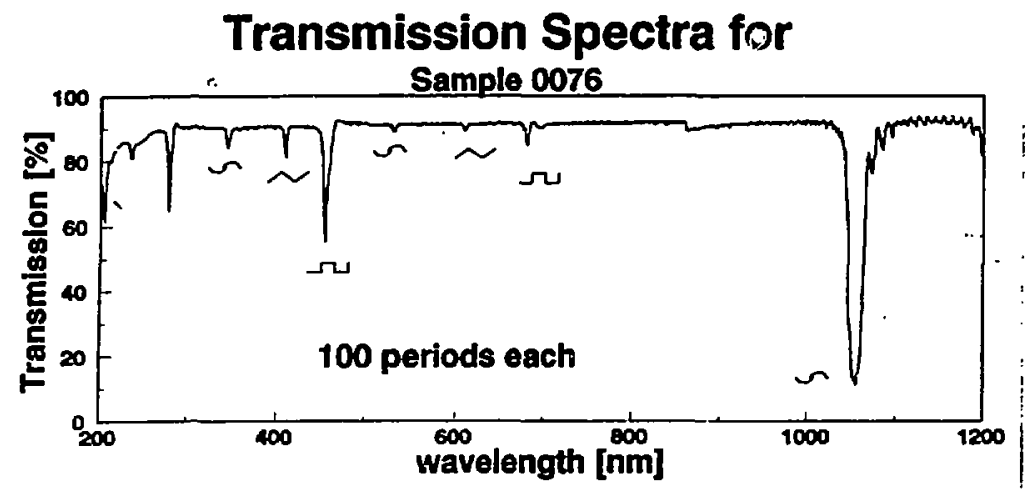

Fig. 6: Reflection curve of an expeximental filter consisting of a stack of three different filters with rectangular, triangular, and sinusoidal refractive index change, respectively; each filter has 100 periods and $\delta=0.025$

Fig. 6 shows the transmission spectra of a stack of 3 filters, each consisting of 100 perlods ( $\delta n=$ 0.025) with refractive index modulations differing in period and form. The main peak comes from the sinusoldal form; the trlangle and square main peaks are at wavelengths longer than $1200 \mathrm{~nm}$. Each waveform type produces harmonics of several orders which are caused - to some extent - by deviations from the setpolnt mass flows.

\section{The RF-Planar CVD-System}

\subsection{Experiments}

Preliminary deposition studies were carrled out in a horizontal silica tube reactor, shown schematically in Fig. 7. The tube was $7.62 \mathrm{~cm}$ in dlameter (expanded to $12 \mathrm{~cm}$ in the reaction zone) and approximately $61 \mathrm{~cm}$ long. The tube was contained in a radlantly heated furnace with the heating zone approximately $30 \mathrm{~cm}$ long. A thimble containing a fused silica substrate on a graphite plate 


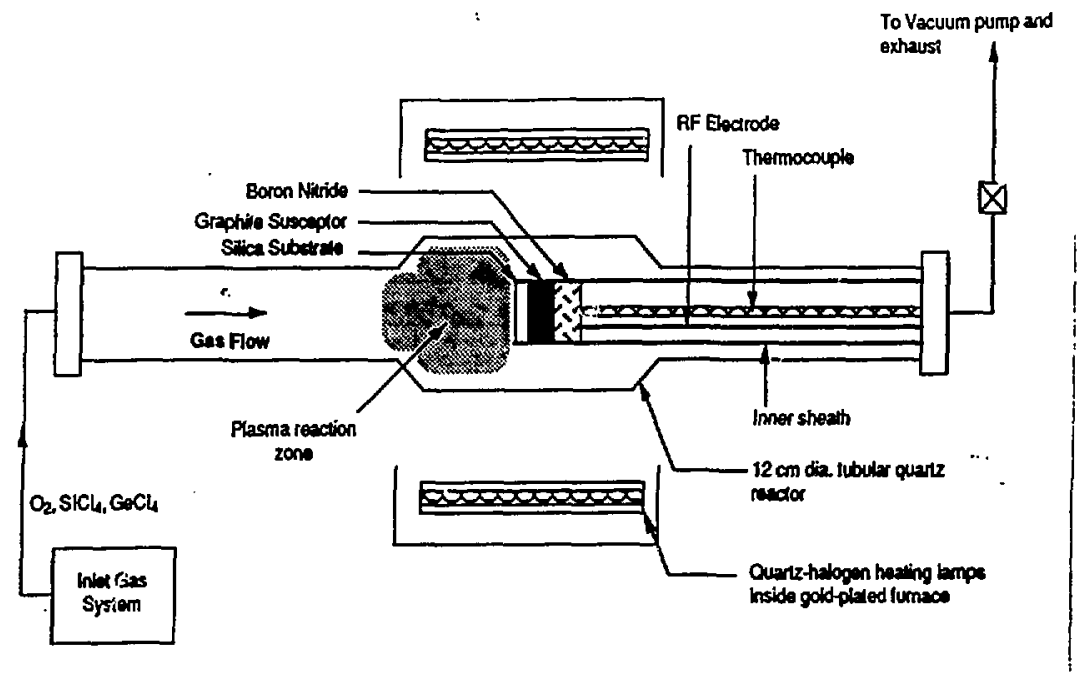

Fig. 7: Schematic of radiantly heated RF-plasma CVD reactor

served as the absorber in the radiant furnace and as the driving electrode for the application of RF at $13.56 \mathrm{MHz}$. Gas flows of $\mathrm{O}_{2}, \mathrm{SiCl}_{4}$ and $\mathrm{GeCl}_{4}$ were established using mass flow controllers. Pressures were monitored with Baratron gauges and controlled by a butterfly valve controller. Typical operating parameter ranges are given in Table 1.

\subsection{Preliminary Deposition Experiments}

Preliminary deposition experiments using $13.56 \mathrm{MHz}$ RF to drive the reactive plasma in the horizontal, radiantly heated furnace pointed out several significant problem areas. Fist, the substrate temperature was difficult to determine. The thermocouple monitor could only read the back of the susceptor anci was influenced by the driving RF electric field. Second, the deposited layers were uneven and contained particulates. The existence of cold walls in contact with the process caused generation of a silica particles, which found its way onto the growing film. Aliso, there was considerable leakage of the plasma into undesirable areas of the reactor, such as directly behind the susceptor and along the walls of the thimble. This leakage significantly reduced the plasma power density available in the reaction volume. In addition, the total RF power available was only $1 \mathrm{~kW}$. 
Table 1: Summary of typical operating conditions used in our preliminary radiant reating RF-plasma CVD experimerts

$\begin{array}{ll}\text { Pressure } & 0.3-3.0 \mathrm{torr} \\ \text { Flow rate oxygen } & 100-500 \mathrm{sccm} \\ \text { Flow rate } \mathrm{SiCl}_{4} & 20-90 \mathrm{sccm} \\ \text { Fiow rate } \mathrm{GeCl}_{4} & 0-10 \mathrm{sccm} \\ \text { RF power (CW exp.) } & 300 \mathrm{Watts} \\ \text { RF power (peak) } & 57-94 \text { Watts } \\ \text { RF power (average) } & 8.5-15 \mathrm{Watts}^{-} \\ \text {Pulse width } & 10-15 \cdot 10^{-3} \mathrm{~s} \\ \text { Pulse Repetition Frequency } & 10-30 \mathrm{~Hz} \\ \text { Temperature } & 1050-1250^{\circ} \mathrm{C} \\ \text { Reaction time } & 60 \mathrm{~min} \\ \text { Number of experimental runs } & 16\end{array}$

\subsection{Hardware Development}

Based on the results of the preliminary irivestigations, a coating system was specifled by LNL and designed and bulit by Prototech Research Inc. A schematic of the coating chamber is shown in Fig. 8. It is capable of handling fused silica substrates up to $15 \mathrm{~cm}$ in diameter and $1 \mathrm{~cm}$ thick. The furnace is a 3-zone backheating system designed to heat the substrates to about $1000^{\circ} \mathrm{C}$. Some tetails regarding the reaction environment are described in Table 2.

Table 2: Sumary of designed operating characteristics of the high temperature, RF-plasma CVD coating system

Substrate Size

Oxygen Flow Rate

$\mathrm{SiCl}_{4}$ Flow Rate

$\mathrm{GeCl}_{4} \mathrm{Flow}_{\text {Rate }}$

RF Power

Substrate Temperature
$15 \mathrm{~cm}$ dia. $\times 1 \mathrm{~cm}$ thick

0-8 sccm

0-2 sccon

$0-500 \mathrm{sccm}$

$24 \mathrm{~kW}$ maximum

$1000^{\circ} \mathrm{C}$ nominal, $1200^{\circ} \mathrm{C}$ max. 


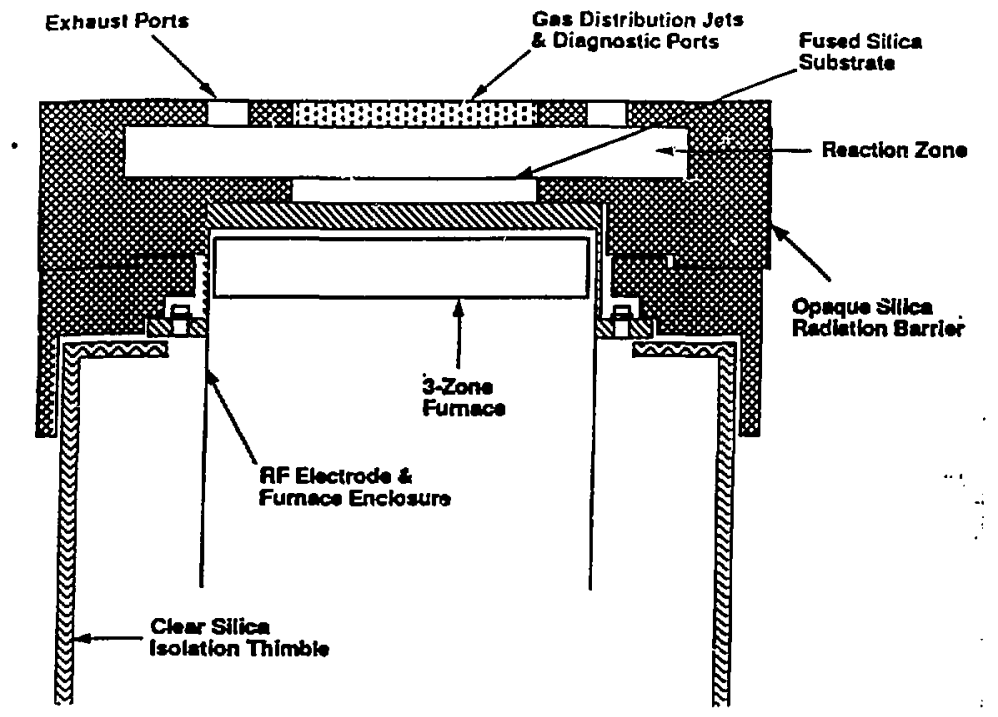

Fig. 8: Schematic drawing of the RF-PCVD coater reaction chamber

The "hot wall" reactor is formed by using closed-cell porous sillca glass to enclose the reaction volume and absorb radiant energy from the furnace. Gas is injected through a top plate via an array of gas injection ports and exhausted out the top at the periphery of the substrate. The containment vessel for the furnace acts as an electrode for a $24 \mathrm{~kW} 13.56 \mathrm{MHz}$ RF-generator. Plasma confinement is achieved by isolating the walls of the electrode with a sllica thimble which is evacuated to less than $10^{-4}$ torr. The absorking sillica provides dielectric insutation to suppress plasma breakdown outside of the reaction chamber. The coating apparatus is located in a clean box to prevent particulate contamination. This coater is designad to be as thexible as posslble to allow for design changes to meet coating process demands.

\section{The Microwave Plasma Planar CVD-System}

\subsection{Status of achieved results}

Multilayer systems designed for high reflectance at $1064 \mathrm{~nm}$ were prepared at the Inner surface of quartzglass tubes [1.7]. Typical deposition parameters are given in Table 3. Enhancing the substrate temperature increases the diffusivity and decreases the incorporation efficlency of fluorine into the $\mathrm{SiO}_{2}$ network. Because the geometrical dlstance between a maximally F-doped and an 
Table 3: Typical deposition parameters for high temperature microwave PICVD

\begin{tabular}{ll}
\hline tube type & Heralux WG \\
tube size & $20 \mathrm{~mm} \times 1.4 \mathrm{~mm}$ \\
tube temperature & $850^{\circ} \mathrm{C}$ \\
pressure & $3 \mathrm{mbar}$ \\
oxygen-mass flow & $200 \mathrm{ml} / \mathrm{min}$ \\
SiCl $_{4}$-mass flow. & $50 \cdot$ \\
$\mathrm{CCl}_{2} \mathrm{~F}_{2}$-mass flow & $10 \cdot$, maximal \\
modulation & sinusoldally \\
period time & $9.5 \mathrm{E}$ \\
No. of periods & 500 \\
\hline
\end{tabular}

undoped $\mathrm{SiO}_{2}$ layer is $181 \mathrm{~nm}$ only, the substrate temperature should be as low as possible in order to prevent a smoothening of the refractive index difference by diffusion. On the other hand the lower temperature limit is given by the temperature for low stress depositior. These aspects lead to a substrate temperature of $850^{\circ} \mathrm{C}$.

Fig. 9 shows a segment of a broken quartzglass substrate with a deposited multilayer system. There is no boundary vislble between substrate and coating. demonstrating the glassy structure of the coating. Wet etching of such samples with a HF containing solution transforms the perlodical index difference to a periodical surface profile due to the dopant content dependence of the etching rate. A SEM plcture of a section of a $\mathbf{5 0 0}$ perlod system is displayed in Fig. 10. The distance from layer to layer (1. e. in the SEM picture from the black/white to the white/black interface and vice versa) is $181 \mathrm{~nm}$ corresponding to $1064 \mathrm{~nm} / 4 \mathrm{n}$. No defects $\alpha$ deviations can be seen in the array. Laser damage threshotds measured at Lawrence Livermore Natlonal Laboratory with $10 \mathrm{~ns}$ laser pulses at $1064 \mathrm{~nm}$ exceed $40 \mathrm{~J} / \mathrm{cm}^{2}$ for both F- and Ge-doped multilayer systems; however, because of the curved substrates these measurements were quite difficult to perform and the results are estimated to be pessimistic values.

\subsection{Planar depositions}

A Rugate filter with a small on $(<0.02)$ has a very narrow reflection peak of typically $10 \mathrm{~nm}$ halfwidth at $1064 \mathrm{~nm}$. So the uniformity of the deposition rate across the substrate should be at least $1 \%$ so that the reflections peak coincides with the laser wavelength all over the substrate area. Because of the essential importance of the film uniformity, the development of the planar micro- 
wave coater is done in two steps. At tirst the coater design and the operation parameters are optimized emperically by using a setup made for room temperature depositions. On the basis of these experiences the concept for a high temperature coater has been developed, which is being built at present at SCHOTT.

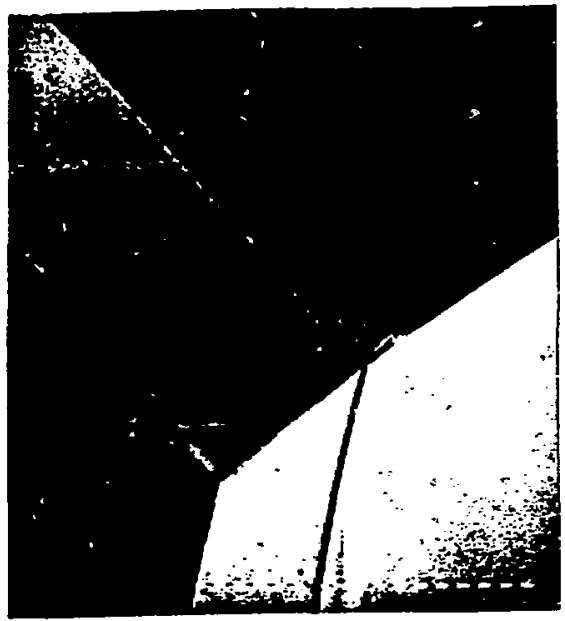

Fig. 9: Broken substrate tube with deposited multilayer system

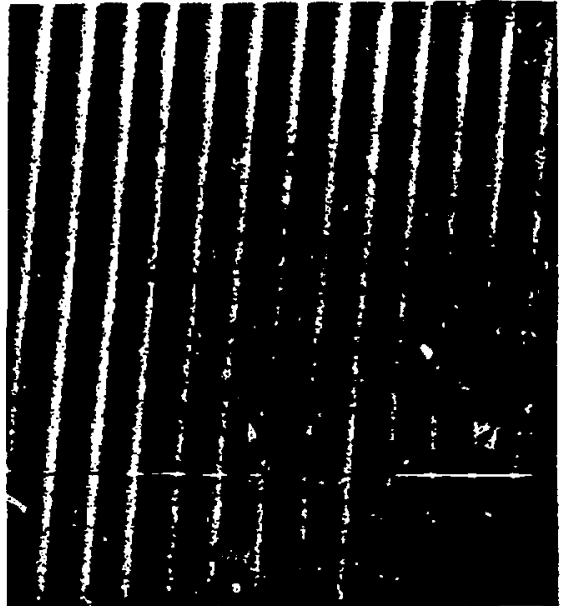

Fig. 10: SEM-picture of an etched multilayer (lin' :orresponds to $i \mu \pi)$

The experimental arrangement of the room temperature coater is shown in Fig. 11. The substrate is placed on a base plate (glass) below a gas distributor inside a glass bell jar. through which the exhaust gas is pumped off. The gas distributor consists of a $5 \mathrm{~mm}$ thick aluminum plate with holes of $1.2 \mathrm{~mm}$ diameter drilled inte it every $5 \mathrm{~mm}$ and a gas plenum above it. The reaction gas is fed into the gas plenum via a small tube with 13 holes at the end, which provide a uniform distribution of the gas over the 450 distributor holes. The microwave power is applied by an antenna below the tase plate. The whole apparatus is surrounded by a shielding cage to avoid any leakage of the microwave. The metallic gas distributor plate acts as an upper confinement for the propagation of microwave. With propper tuning it is possible to ignite a stable plasma of $120 \mathrm{~mm}$ diameter right above the substrate with a pulse power of $3-4 \mathrm{~kW}$ (in 1 mbar $\mathrm{O}_{2}$ plus $1 \% \mathrm{TiCl}_{4}$ ).

The film uniformity . can easily be estimated from the colours of the interference patterns of a $\mathrm{TiO}_{2}$ film deposited from a $\mathrm{TiCl}_{4}$ plasma due to the high refractive index of $\mathrm{TiO}_{2}$. Quantitative values of 


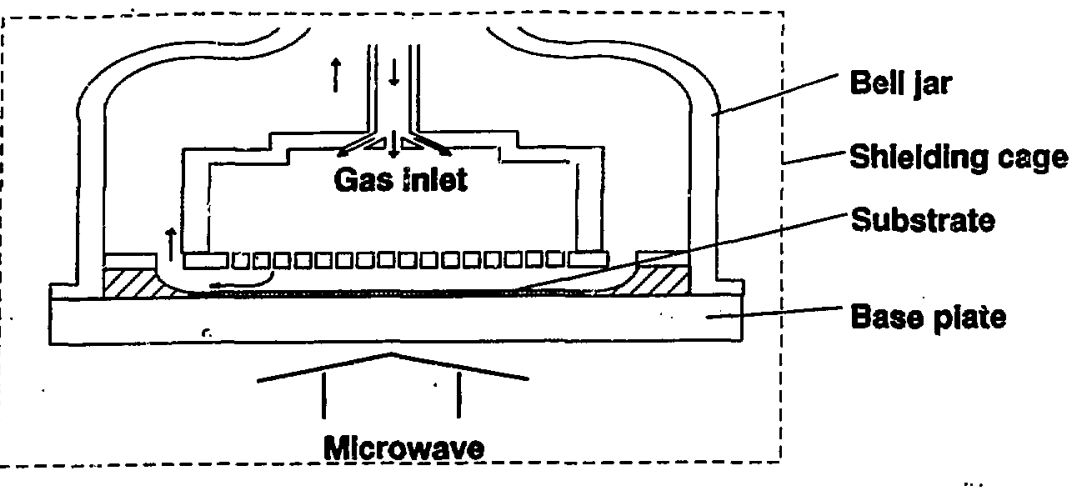

Fig. 11: Schematic drawing of the microwave PICVD reaction chamber for room temperature experiments

(Tro[2]-Film, sample 325)
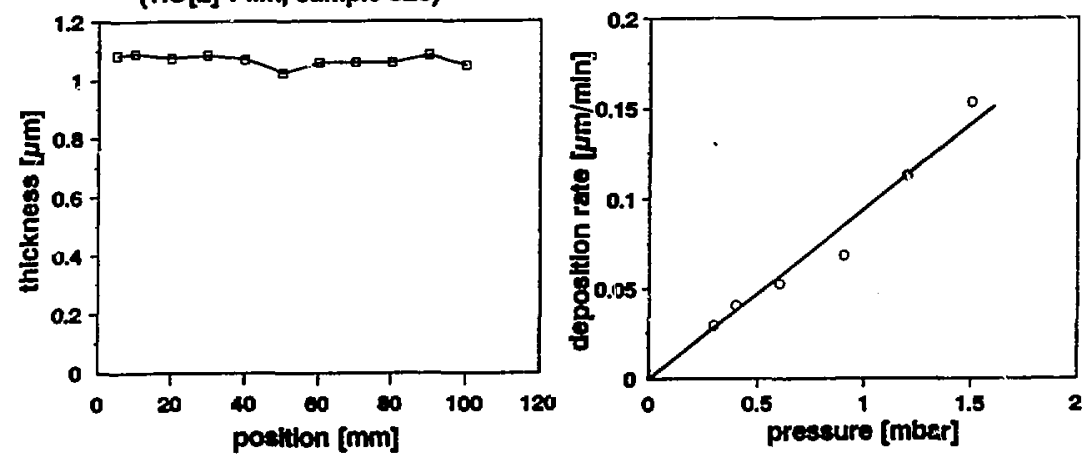

Fig. 12: Thickness homogeneity of a PICVD-deposited $\mathrm{TiO}_{2}$-film measured across the substrate

Fig. 13: Deposition rate versus pressure for: $\mathrm{TiO}_{2}$-deposition at room temperature

the film thickness are obtained by covering a stripe of the substrate during deposition and measuring the helght of the edge with an Alpha step $200 \mathrm{film}$ proflle (Tencor Instruments). A typical result of a thickness measurement across the substrate is shown in Fig. 12. The film thickness is rotationally symmetric in most cases. With optimal parameters, listed in Table 4, the maximum devi- 
ation of the thiciness from the average value is $i 3 \%$ at this state of aeveiopment. The possibility to improve the uniformity by mechanical movement of the substrate was not considered.

The deposition rate varies linearly with pressure as shown in Fig. 13. In this experiment the mass flow was increased proportional to the pressure in order to keep the gas velocity constant and thus not alter the gas exchange in the reactor. The deposition rate will be 20 times higher for $\mathrm{SiO}_{2}$ deposited at high temperature due to a larger amount of source chemical $\left(20 \% \mathrm{SiCl}_{4}\right.$ in $\left.\mathrm{O}_{2}\right)$ possible in the high temperature process and will typically reach $1-2 \mu \mathrm{m} / \mathrm{min}$.

Table 4: Typical parameters for $\mathrm{TiO}_{2}$ microwave-PICVD deposition at room temperature

$\begin{array}{ll}\text { substrate diameler } & 120 \mathrm{~mm} \\ \text { pressure } & 0.7 \mathrm{mbar} \\ \text { oxygen-mass flow } & 100 \mathrm{ml} / \mathrm{min} \\ \text { TiCl }_{4} \text {-mass flow } & 1.0 \mathrm{ml} / \mathrm{min} \\ \text { pulse power } & 4.0 \mathrm{~kW} \\ \text { pulse duration } & 0.8 \mathrm{~ms} \\ \text { pulse pause } & 90 \mathrm{~ms} \\ \text { average power } & 35 \mathrm{Watts} \\ \text { deposition rate } & 33 \mathrm{~nm} / \mathrm{min} \\ \text { uniformity of thickness } & \pm 3 \% \\ \text { refractive index of } \mathrm{TiO}_{2} & 2.5(\mathrm{at} 500 \mathrm{~nm})\end{array}$

\subsection{Conclusions}

The PICVD process is well suited for the preparation of multilayers. Important features are:

- a quarterwave layer is composed of many monolayers in the nanometer range;

- both high deposition rate and arbitrary refractive index profiles are feasible simultaneously;

- Low refractive index dfference and a high number of layer pairs can be realized;

- multilayer thickness can amount to the mm range;

- laser damage thresholds are very high.

\section{Conclusions}

We have recently shown that very high damage threshold dielectric coatings can be made using plasma CVD at high temperatures $\left(1000^{\circ} \mathrm{C}\right)$ [1]. In this paper we discussed ou efforts at scaling this process to larger, flat substrates (10 cm diameter) as well as comparing RF and microwave plasmas. There are tour main technical issues that must bolved to successfully implement this 
coating process:

1. Uniform deposition ( \pm 1-5 \%) over a large area

2. High deposition rates (1-4 $\mathrm{mm} / \mathrm{min})$

3. Uniform substrate heating of temperatures up to about $1000^{\circ} \mathrm{C}$

4. Minimal dopant diffusion

In addition, racik is in progress to look at the effects of RF versus microwave diven plasma on the deposition process and we have begun to identify and refine plasma characterization techniques. Based on these results we have built a large coating system designed to coat substrates up to about $15 \mathrm{~cm}$ in diameter with several thousand quarter-wave layers of atternating doped and undoped $\mathrm{SiO}_{2}$. Detalls of the coater design specifications have been formulated and given. The system is expected to be fully operational by mid-1990.

\section{Acknowledgement}

We would like to thank Dr. U. Fotheringham for the theoretical calculations, Mr. Messinger for optlcal measurements as well as Mrs. Blecker and Mrs. Blenefeld for the PICVD-experiments.

References:

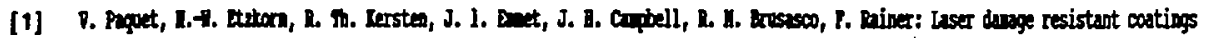

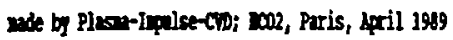

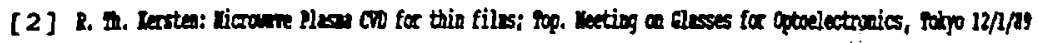

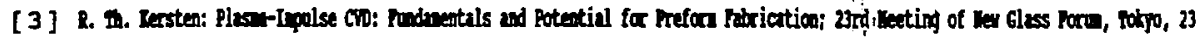
Jumary 1989

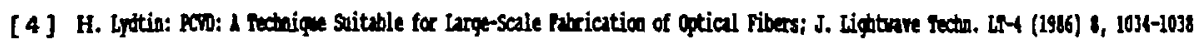

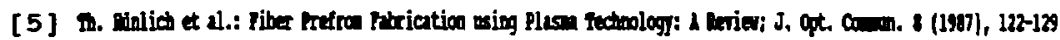

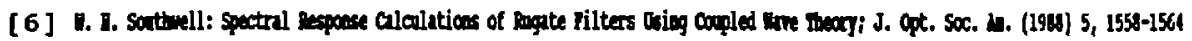

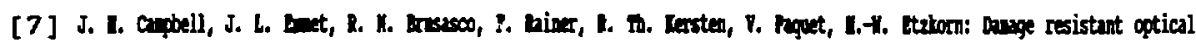

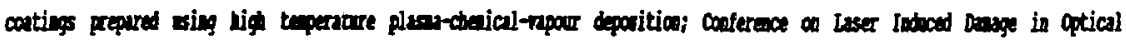
Materials, boulder 195s; mIS special poblication (in peess) 